\title{
Psalm 137: 'n (On)Christelike Psalm? ${ }^{1}$
}

L P Maré

(AGS Teologiese Seminarium)

\section{ABSTRACT}

\section{Psalm 137: An Unchristian Psalm?}

Christians tend to be horrified and embarrassed by the bloodthirstiness of Psalm 137, especially in the light of Jesus' command to forgive one's enemies. A prayer, which rejoices in the cold blooded murder of innocent children, seems totally unchristian. However, the psalm is part of the Christian canon, and therefore it cannot be ignored. It is the aim of this article to show that Psalm 137 can and should take its rightful place in the life and worship of the Christian Church.

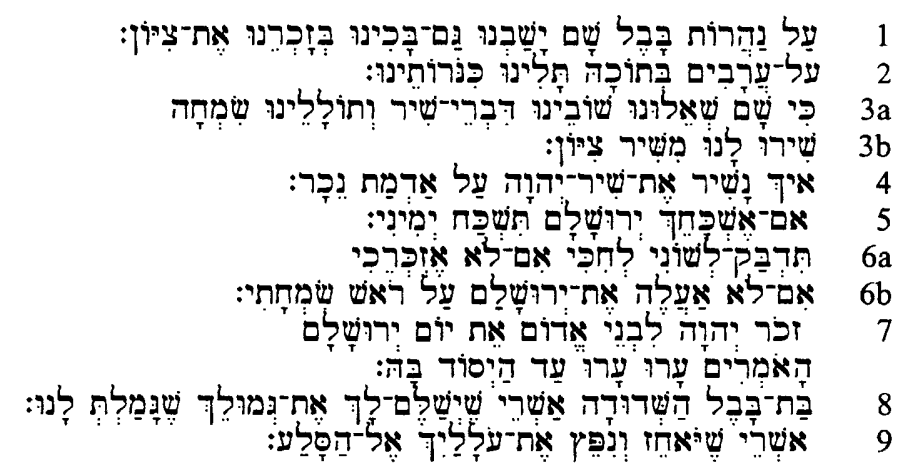

\section{INLEIDING}

Christengelowiges beskou Psalm 137 (veral stiges 7-9) as wreed en bloeddorstig en totaal onchristelik(!), veral in die lig van die opdrag van Jesus dat 'n mens sy vyande moet liefhê (Matt 5:44). "Christian commentators have tended to be horrified by the bloodthirstiness of Israel's wish" (Levine 1995:185). Bright (1975:234) wys daarop dat stiges 7-9 ontbreek in die gesangeboek van sy gemeente. Hy skryf dat hy in 'n mate hieroor bly is omdat dit 'n skokkende teks is en dit 'n verleentheid sou wees om so 'n teks tydens 'n erediens te lees (1975:235).

\footnotetext{
${ }^{1}$ Hierdie artikel spruit voort uit navorsing wat aan die Randse Afrikaanse Universiteit gedoen is.
} 
Dit is egter so dat Psalm 137 in die Christelike kanon opgeneem is, en as sulks kan dit nie ignoreer word nie. Psalm 137, met sy bloeddorstigheid, het ' $n$ bepaalde rol en funksie in Christelike aanbidding. In hierdie artikel word die verbruikersvriendelikheid van Psalm 137 in Christelike konteks van naderby beskou.

\section{GATTUNG EN SITZ IM LEBEN}

Ten opsigte van die Gattung is daar nie volkome eenstemmigheid onder navorsers nie. Burden (1991:122) meen dat die klem van die gedig op Sion val en tipeer dit dan as "'n ongewone Sionslied wat klaag - en vloekelemente bevat" (vgl ook Allen 1983:238, 241).

Terwyl dit waar is dat die Sionstradisie 'n prominente plek in die psalm inneem, is die dominante tema rondom Sion hier nie vreugde nie, maar wel droefheid. Die psalm self maak egter daarop aanspraak dat dit vir die volk in ballingskap nie moontlik was om Sionsliedere te sing nie (stige 4), alhoewel hulle spottenderwys daarvoor gevra is deur hulle verdrukkers (stige 3). Terwyl die psalm dan self die sing van Sionsliedere in die vreemde as onmoontlik beskou, is dit eintlik onmoontlik om dit as 'n Sionslied te tipeer.

Myns insiens moet die psalm as 'n klaaglied van die volk tipeer word. Die psalm bestaan struktureel uit die volgende elemente: Strofe 1 (1-4) is duidelik die klag van die volk, terwyl strofe 2 (5-6b) as selfbeklag of selfverwensing beskou kan word. Die Sionslied word dus op sy kop gekeer, en in plaas van vreugde, word die bitterheid en droefheid van die volk beklemtoon. Die derde strofe (7-9) is 'n vervloeking van die vyand wat vervat word in die vorm van 'n petisie wat tot God gerig word. Hierdie elemente van klag en petisie (vervloeking) vorm 'n integrale deel van die struktuur van die klaagpsalms (vgl Brueggemann 1984:54-55).

Die situasie wat in Psalm 137 voorgehou word, is dié van die ballingskap in Babel. Kraus (1989:501) meen selfs dat hierdie die enigste psalm is wat met volkome sekerheid dateer kan word. Dit blyk volgens stige 8 dat die Babiloniese Ryk nog bestaan. Die digter kyk egter terug na die ballingskap wat reeds verby is. Stiges $1-3$ is almal in die perfektum geskryf, wat dui op 'n gebeurtenis wat afgehandel is. Of die digter die ballingskap self beleef het, is 'n ope vraag, maar "the passionate pathos of vv 1-4 may suggest that he spoke from experience" (Allen 1983:239, vgl ook Fohrer 1993:133).

Die kultiese agtergrond van die psalm moet dan gesien word as "an observance of lamentation by the exiles" (Kraus 1989:502), en nie net as 'n lied wat 'n spesifieke episode in Israel se geskiedenis oorvertel nie. Die psalm is in die latere Joodse tradisie op die negende van die maand $\mathrm{Ab}$ gebruik tydens die diens wat die vernietiging van Jerusalem in herinnering geroep het (Allen 1983:239; Kellerman 1978:54; Levine 1995: 
185). 'n Sterk moontlikheid bestaan dat dit van die begin af teen so 'n kultiese agtergrond funksioneer het. Die psalm het moontlik ook funksioneer op een van die "Days of Lamentation" waarop daar spesifiek gebid is vir die restorasie van die land en die volk (Anderson 1981:897; vgl Sag. 7:1-5).

\section{TRADISIES EN TEMAS IN PSALM 137}

Daar is net een tradisie wat in hierdie psalm figureer, naamlik die Sionstradisie. Sion is deur die volk as die woonplek van God (Ps 76:3; Jes $8: 18$ ), as die simbool van God se teenwoordigheid in hulle midde, gesien. Daarom sou Sion nooit wankel nie en sou dit altyd met hulle goed gaan. $\mathrm{Al}$ sou nasies daarteen optrek, sou Jahwe self die aanvalle afweer en die stad beskerm (Ps 48:3-8). Dit was veral die profete wat hierdie tradisie opgeneem en 'n belangrike plek in die volk se teologie gegee het as simbool van "unrestricted safety and security with Yahweh" (Von Rad 1962:47).

Sion was dus ' $n$ simbool van sekuriteit en sterkte en 'n bron van vreugde. In Psalm 137 is Sion egter nie meer 'n bron van vreugde nie, maar die oorsaak van droefheid. Die volk dink terug aan Sion, nie met blydskap nie, maar wel met hartseer. Sion is verwoes. Die sekuriteit wat hierdie anker gebied het, is vernietig. Die Sionstradisie word dus op sy kop gekeer, wat die gevoel van ontredderdheid en bitterheid baie skerper in fokus bring.

Baie nou verbonde aan die Sionstradisie is die tema herinnering aan Sion/Jerusalem. Aangesien Sion so 'n sentrale plek in Juda se teologiese denke ingeneem het, was die val van Jerusalem en die gepaardgaande verwydering van Sion 'n geweldige traumatiese gebeurtenis. Die herinnering aan Sion het die ballinge met groot droefheid en verlange vervul, aangesien die vreugde van die teenwoordigheid van Jahwe in die tempel, en hulle ontmoeting met Hom aldaar, slegs in hulle gedagtes voortbestaan het. Daarom was dit vir hulle onmoontlik om in 'n vreemde land 'n Sionslied te sing. Tog beklemtoon stige 6 dat hulle, ten spyte van die feit dat die sing van 'n Sionslied in 'n vreemde, onrein land nie moontlik is nie, Jerusalem/Sion nooit sal vergeet nie, want dit bly die objek van hulle grootste vreugde.

Die tema van afwesigheid van vreugdesang in stige 4 is reeds hierbo aangeraak. Die nuwe situasie van ontredderdheid en droefheid en verwydering uit Sion, het vreugdeliedere onmoontlik gemaak. Hier vind ons weer eens 'n voorbeeld waar die situasie die gebruik van die Gattung bepaal. In tye van krisis is Sionsliedere, liedere van vreugde, nie moontlik nie, maar verhef die gelowige sy stem in 'n klaaglied om sy ervarings en emosies voor God te verwoord.

Die tema van droefheid word eksplisiet in stige 1 genoem, maar dit kom ook in die res van die psalm na vore. Juda het hulle siters aan die 
bome opgehang, hulle kon nie Sionsliedere sing nie (stiges 2-4). Dit gee alles uitdrukking aan die intense droefheid wat hulle ervaar het as gevolg van hulle ervaring van ontredderdheid. In stige 1 word die droefheid van die ballinge gekoppel aan hulle herinnering aan Sion. Jerusalem is ingeneem, die tempel is verwoes, die ballinge is weggevoer na ' $n$ vreemde land, weg van Sion wat hulle bron van sekuriteit en vreugde was. Hier in die vreemde kan hulle nie anders as om te ween wanneer hulle hierdie verskriklike gebeurtenis in herinnering roep nie. Juda se droefheid stop egter nie met hulle trane nie. Hulle droefheid is nie sonder hoop nie, maar dit is 'n droefheid wat oorgaan tot 'n magtige protes en uitroepe van wraak wat daarop gerig is om Jahwe se hand in beweging te bring ten gunste van sy volk en ter wille van sy verhouding met hulle (vgl Brueggemann 1997a:436-438).

Die tema hoon van die vyande kom in stige 3 ter sprake. Diegene wat Juda in ballingskap weggevoer het, het honend met hulle gespot deur hulle te vra om Sionsliedere te sing. Dit gaan nie hier net om die vreemde verdrukkers wat daarop uit is om pret te hê met die gevangenes wat hulle met hulle sang moet vermaak nie, maar hierdie uitdrukkings lê op 'n dieper vlak: "As far as motif criticism is concerned, they belong to the area of mocking questions asked by the enemies ('Where is their God now?' Cf. e.g. Pss. 79:10; 115:2)" (Kraus 1989:503). Daar word dus nie net met Israel gespot nie, maar met Israel se God. Die verdrukkers wil eintlik aan Juda voorhou dat hulle God hulle vergeet en verlaat het, dat Hy inderdaad maar ' $n$ swak God is, wat nie in staat was om hulle in hulle dag van benoudheid te red nie.

Die tema van selfverwensing kom in stiges 5-6 ter sprake. Die digter wil eerder verlam en stom wees as wat hy Jerusalem vergeet. Indien sy regterhand lam geword het, en indien sy tong aan sy verhemelte gekleef het, sou hy nie daartoe in staat wees om weer sang en musiek tot eer van God te bring nie. Hy sou dus nie meer sy regmatige plek in die kultiese lewe van die volk kon inneem nie (Waaijman 1986:174). Om Jerusalem te vergeet, sou inderdaad beteken dat Hy God vergeet, "seeing that the power of the living God is revealed in the fate of Jerusalem, in her fall and in her rebuilding for which the poet longs" (Weiser 1962: 796).

Die tema van vreugde word in stiges 3 en 6 te berde gebring. Die gedagte van vreugde word hier aan Sion/Jerusalem gekoppel. Die tema word ironies deur die digter angewend, want in hierdie psalm gaan dit eintlik om die afwesigheid van blydskap. Aangesien Jerusalem verwoes is, kan daar geen vreugde wees nie, daarom is dit ironies dat die verdrukkers "vreugde" vra van die ballinge deur die sing van 'n Sionslied. Tog is Jerusalem die objek van die digter se grootste vreugde (6). Alhoewel vreugdesange onmoontlik is in die vreemde land, bly die (verwoeste) Jerusalem steeds die bron vir vreugde. 
Die tema van vergelding/vervloeking van die vyande kom ter sprake in stiges 7-9. In hierdie gedeelte bid die digter die oordeel van God af oor diegene wat verantwoordelik was vir die vernietiging van die tempel en Jerusalem en die wegvoering van die volk in ballingskap. Twee volke is die objek van die digter se versugtinge om wraak: Edom en Babel.

Die Edomiete was die afstammelinge van Esau, die broer van Jakob (Gen 36:1). Die optrede van hierdie bloedverwante van Juda was besonder verraderlik op die dag toe Jerusalem ingeneem en verwoes is. In plaas daarvan dat die Edomiete hulle broers ondersteun het, het hulle hulleself aan die kant van die vyand geskaar met ' $n$ bose vreugde oor die vernietiging van die stad (vgl Jes 34:1-17; Jer 49:7-22; Eseg 25:12-14, $35: 1-15$; Ob :1-21). Hulle het die lot van Juda met genot aanskou, en selfs sover gegaan as om van die vlugtelinge uit Juda gevange te neem en aan die Babiloniërs uit te lewer. Hierdie verraderlike optrede van die Edomiete moet deur Jahwe onthou word en Hy moet vernietigend teen hulle optree.

Die wraakuitinge teen Babel is sekerlik van die verskriklikste vergeldingsuitsprake in die hele Bybel. Nie net word daar gebid dat Babel vergeld moet word en sy kinders se koppe inmekaargeslaan word nie, maar die een wat dit doen word gelukkig genoem. Hier gebruik die psalmis 'n seënspreuk (die ישר - formule) om 'n vervloeking teen die vyand te rig om sodoende die teenoorgestelde van geluk te bereik.

Die uitwissing van kinders was soms deel van 'n militêre beleid wat die totale vernietiging van 'n volk ten doel gehad het (vgl 2 Kon 8:12; Jes 13:16; Hos 10:14, 14:1; Nah 3:10). Dit is inderdaad 'n grusame gebed wat hoogs ontstellend is. Dit moet egter verstaan word teen die agtergrond van die ou-Nabye-Oosterse wêreld. Daarby is die vergelding wat afgebid word, uiteindelik ter wille van die Naam en saak van die Here.

Dit is geloof in die krag van God wat hier ter sprake is. Die psalmis bid straf van God af oor die vyande. Hy wil antoon dat die laaste woord deur God gespreek word, en nie deur die vyande wat die Naam van God belaster nie. Dit is ter wille van Homself dat Jahwe nie kan toelaat dat sy majesteit en heerlikheid aangetas word deur die vyande se lastering en spot nie (Weiser 1962:796). Hierdie passievolle verwoording van pyn en woede en wraak is 'n uitroep dat die geskiedenisboeke gebalanseer moet word. Dit gaan nie hier om persoonlike wraaksug om barbaarse vergelding nie, maar daar word gebid vanuit die perspektief van ywer vir Jahwe en sy woonplek (Mays 1994:423; vgl Jes 13:1-22, 47:1-15; Jer 51:164). Hierdie gebed om wraak staan dus in direkte verband met die profete se oordeelsuitsprake wat teen Babilon gerig is.

Die vergelding wat afgebid word, spreek ook van die hoop en vertroue wat die volk in Jahwe stel dat Hy nie sal toelaat dat onreg ongestraf sal bly nie. Die verwoesters van die volk van die Here moet 
weet dat die ballinge se God die enigste lewende God is wat nie vir altyd toornig bly teenoor sy volk nie. God sal nie toelaat dat diegene wat geweld pleeg daarmee sal wegkom nie.

Die tema van die dag van Jerusalem kom in stige 7 voor. Dit is 'n verwysing na die dag waarop Jerusalem gestraf is vir haar sonde teen Jahwe, en God se oordeel oor Juda voltrek is. Hierdie tema hou waarskynlik met die יוֹם יהוה verband, die dag waarop Jahwe in die geskiedenis van volke ingryp om sonde wat tot 'n klimaks gevoer is, te straf (vgl Jes 2:12-17; 13:6, 9; Jl 1:15, 2:1-17; Am 5:18-20, Sef 1:2-18, 2:2-3; Mal 4:1). Israel (en Juda) het aanvanklik gemeen dat die יוזם 'n dag van seën vir hulle, en oordeel oor hulle vyande sou wees. Die profete Amos en Sefanja en andere het egter hierdie tema omgekeer deur aan te toon dat die יוֹם יהוה in die eerste plek die voltrekking van God se oordeel oor sy eie volk sal wees.

Die יוֹם יהוה is dus 'n profetiese tema wat op die oordeel van God dui, eerstens oor sy eie volk, maar ook oor die ander nasies. In Psalm 137 word dit spesifiek met Juda in verband gebring. Dit is die dag waarop die toorn van God in al sy felheid sal losbars oor die volk van die Here, die dag waarop Juda in die gerig gehou word deur die almagtige God wat sonde haat. Dit is die dag waarin die volk van die Here losgeskeur is uit hulle land en van hulle tempel, die dag waarop alles waaraan hulle vasgehou het rondom hulle ineengestort het. Dit is 'n dag wat katastrofale gevolge inhou vir die volk, wat te make het met die verskrikking van die voltrekking van God se oordeel.

Die tema van die ballingskap speel regdeur die psalm ' $n$ belangrike rol. Die wegvoering van Juda in ballingskap kan beskryf word as die donkerste tydperk in die volk se geskiedenis. Die trauma van hierdie gebeurtenis kom sterk na vore in Psalm 137. Al die temas wat reeds bespreek is, hou met die ballingskap verband. Dit het vir die volk verwydering van Sion beteken $(1,3)$, in die vreemde was daar geen vreugdesang moontlik nie $(3,4)$, hulle het intense droefheid beleef $(1)$, hulle was oorgegee aan die hoon en verdrukking van hulle vyande (3). Die vergelding wat hulle afbid oor Edom en Babel is as gevolg van wat hulle aangedoen is met die ballingskap (7-9), die dag van Jerusalem (7) is die begin van die ballingskap. Die selfverwensing van die digter (5-6) hou ook daarmee verband deurdat Jerusalem, die simbool van God se teenwoordigheid steeds as die hoogste vreugde van die digter voorgehou word, te midde van die hartseer van die ballingskap.

\section{PSALM 137 - 'N CHRISTELIKE PSALM}

Kan die wrede en bloeddorstige Psalm 137 in Christelike kringe gebruik word? Of moet die psalm as onchristelik afgemaak word? Myns insiens 
het die psalm gebruikswaarde in die Christelike Kerk. "Even the anger of the refugee or the exile can become an act of prayerful worship" (Pleins 1993:41). Psalm 137 wil juis kommunikeer dat sodanige woorde en gevoelens van wraak en retribusie nie vir God verberg hoef te word nie. Christene ervaar dikwels hierdie gevoelens, maar probeer dit dan vir God verberg, wat ' $n$ onmoontlike saak is. Dit veroorsaak dat Christene oneerlik in hulle verhouding met God is.

Die eerste strofe van die psalm voer die lesers na die ballingskap in Babilon mee. Die situasie in Babilon word in skerp kleure geskets: Hulle sit en huil by die riviere aldaar. Hulle herinnering aan Sion vul hulle met hartseer en verlange. Hulle beleef 'n gevoel van absolute ontredderdheid. Sion is verwoes. Alles waarop hulle gehoop het, is vernietig. Hulle droefheid word verhoog deurdat hulle oorheersers van hulle verwag om in hierdie toestand van verlatenheid en droefheid 'n Sionslied, wat gewoonlik op die Sionsberg tot eer van Jahweh gesing is, te sing. Die Babiloniërs se doel met die sing van hierdie liedere was nie die eer van Jahwe nie, maar hulle wou inderwaarheid voorhou dat Jahwe magteloos is. Die opdrag om te sing wil dus ' $n$ karikatuur van Israel se godsdiens en 'n bespotting van Jahwe maak (Mays 1994:422).

Die volk weier egter om hierdie opdrag uit te voer. Hulle sien nie kans om 'n Sionslied, wat tot Jahwe se eer moet strek, tot die vermaak van hulle heidense oorheersers te sing nie. 'n Sionslied, 'n lied van vreugde en blydskap, sou onvanpas wees in 'n situasie van droefheid en verlatenheid. "Not every place and hour, not every inward frame of mind and not every human environment, is suitable for sounding forth God's praise" (Weiser 1962:795). In hulle aanbidding kon Israel nie anders as om aan hulle gevoelens van droefheid uiting te gee nie, daarom sien hulle nie kans vir ' $n$ lied van vreugde nie. Die situasie bepaal die Gattung van klaaglied.

In die tweede strofe kom die digter se lojaliteit teenoor Jerusalem skerp in fokus. Die bedoeling van die digter is nie dat Jahwe slegs in Jerusalem aanbid kon word nie. Hy wil juis aantoon dat die verwydering van Jerusalem die volk tot 'n ander aspek van aanbidding bring: die klaaglied. Die negatiewe situasie waarin die volk hulleself bevind, beteken nie die einde van aanbidding nie, dit beteken wel dat ' $n$ ander faset van aanbidding sterker op die voorgrond tree. "The voice of faith 'there' was the voice of prayer with tears" (Mays 1994:422).

In strofe drie kom die klag van die volk sterk in fokus: Jahwe word gevra om Edom se optrede tydens die verwoesting van Jerusalem in herinnering te roep. Jahwe durf nie toelaat dat hierdie verraderlike optrede van hulle bloedbroers ongestraf bly nie. Stiges 8-9 vorm die hoogtepunt van die vervloeking. Die klem van die vervloeking val op Babilon. Hier vind 'n omkering van Babilon se posisie plaas. In stige 1 was Babilon

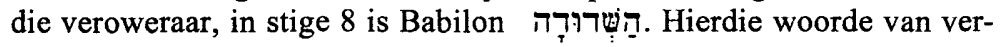


vloeking roep Jesaja 13:15016, wat 'n Godspraak van Jahwe teen Babilon is, in herinnering.

Psalm 137 (veral die laaste strofe!) moet sekerlik in die lig van sy eie tyd en omstandighede verstaan word. Mens moet in gedagte hou dat die digter van eietydse terme en beelde rondom oorlogvoering gebruikmaak. Die digter bid hier dat die beginsel van lex taliones toegepas moet word. Babilon moet in gelyke maat vergeld word vir dit wat hulle aan die volk van die Here gedoen het.

Die vraag bly egter: hoe moet die gelowige vandag Psalm 137 haneer? Die beginsel van lex taliones word skynbaar deur Jesus afgewys in Mattheüs 5:38-42. Is Pleins (1993:41 - sien hierbo) se aanmerking dat hierdie psalm wel 'n rol te speel het in Christelike aanbidding korrek? Wat is daardie rol? Kan 'n Christen vandag so 'n gebed bid? Anderson (1983:88) vra of die psalm nie dalk 'gesensor' moet word nie. Hyself dink nie so nie, maar Holladay (1993:304-305) vermeld dat die laaste strofe van hierdie psalm in die 'Roman Catholic Liturgy of the Hours' weggelaat word. Moet die psalm dalk, volgens die denke van Bright (1975:238), beskou word as die woorde van 'n voor-Christus-mens, 'n tipe mens wat van God se Gees vervreemd was?

Die korrekte antwoord op die probleem van die gebruik van die psalm moet eerder gesien word in die feit dat die spreker van hierdie psalm nie self tot aksie oorgaan nie. Hy verpletter nie die babas se koppe teen die rotse nie, hy vernietig nie self sy vyande nie. Dit is 'n gebed, 'n verlange, ' $n$ begeerte wat hy tot God rig dat reg en geregtigheid moet geskied. Dit is uiteindelik ' $n$ bevrydende daad van eerlike geloof waardeur hy sy wraakgedagtes in God se hande oorgee om op te tree soos Hy wil (vgl Brueggemann 1984:77).

Juda het nie oor die fisiese vermoëns beskik om self wraak uit te oefen nie. Die enigste wapen wat Israel tot sy beskikking gehad het, was woorde, woorde wat tot God gerig is waardeur hulle ervaring van magteloosheid en vernedering, hulle gedagtes van vergelding en woede, verwoord is. Levine (1995:185) noem dit die "verbal counterpart to the alltoo-real bloodshed in the streets of Jerusalem at the time of the destruction". Hierdie retoriek van geweld word geuiter deur mense wat oor geen ander wapen as woorde bekik nie, mense wat andersins magteloos sou wees. Hierdie retoriek is aan die kant van die "re-establishment of justice and the redress of abuse" (vgl Brueggemann 1997b:244).

Psalm 137 kommunikeer dat die Christen vandag eerlik moet wees teenoor God ten opsigte van sy emosies en ervarings. Dit kom duidelik na vore dat die digter niks gedoen het om wraak te neem nie, maar dat hy sy gevoelens van wraak verwoord het. Israel se wapen was woorde en nie dade nie. Die digter bid wraak en gewelddadige vergelding teen Edom en veral Babilon af, maar hy vra nie toestemming om dit self uit te voer nie. 'n Verdere belangrike saak is dat hierdie woorde tot God gerig 
is (vgl Brueggemann 1986:70). Die regverdige het die reg om te respondeer op geweldpleging. Hierdie respons behels dat die uitoefening van wraak nie in eie hande geneem word nie, maar in God se hande verplaas word. Dit is net God wie se wraakneming regverdig is, daarom mag net Hy dit uitoefen.

Die Bybel spreek op talle plekke die gedagte uit dat wraak aan God behoort (Ps 94:1; Jes 63:4; Rom 12:19; Heb 10:30). Wanneer die Christen sy wraakgedagtes aan God verwoord, gee hy erkenning aan hierdie feit. Hy doen egter nog meer: hy gee sy wraak vir God, en op daardie wyse word hy bevry van sy gedagtes van wraak, en kan hy tot nuwe lewe toetree.

Jesus het geleer dat ons mekaar moet vergewe (Matt 6:12). Die verbalisering van gedagtes van vergelding en wraak by God is myns insiens deel van die proses van vergifnis. Om te vergewe is nie maklik nie. Daar moet erns gemaak word met die gedagtes en emosies van wrak en woede wat mense ervaar wanneer hulle intense lyding as gevolg van een of ander traumatiese gebeurtenis in hulle lewe beleef. Wanneer 'n mens eerlik voor God kom en hierdie emosies aan Hom bekend maak, gee hy dit oor in sý hande en vind daar bevryding plaas in die innerlike wese van die mens. Dit stel hom dan in staat om te kan vergewe. Wraak en woede wat aan God oorgegee is, loop uiteindelik op vergifnis uit. In daardie lig beskou, kan 'n mens selfs sê dat Psalm 137 na die kruis van Jesus wys, waar God self die "pain of victimization for the sake of the victimizers" gedra het (vgl McCann 1993:120).

Hedendaagse Christelike aanbidding skep soms die indruk dat die gelowige geen negatiewe ervarings of gevoelens mag hê nie. Dit is natuurlik onwaar. Christene moet net leer dat hulle negatiewe emosies nie onderdruk hoef te word nie, maar dat hulle dit tot God kan verwoord as deel van aanbidding. Psalm 137 bevestig dat aanbidding nie net lof bevat nie, maar ook klag. Wanneer die postmoderne gelowige soortgelyke situasies soos dié van Psalm 137 beleef, kan hy sekerlik Psalm 137 in sy totaliteit bid. In sulke situasies is droefheid, woede en wraakgedagtes onvermydelik.

Die gebruik van Psalm 137 is vandag baie relevant in Suid-Afrika. Hoeveel slagoffers van die wreedste misdaad is daar nie vandag nie. Wat moet die Christengelowige doen in so 'n situasie? Wat staan hom te doen wanneer daar gewelddadige misdaad teenoor homself of sy geliefdes gepleeg is? Moet die gelowige geweld met geweld beantwoord? Moet hy/sy die beginsel van lex taliones toepas? Hierop is die antwoord sekerlik NEE. Die gelowige beantwoord nie geweld met geweld nie. Die realiteit van die saak is egter dat Christene wat slagoffers van een of ander vorm van onreg en misdaad geword het wel emosies van woede en wraak en vergelding, selfs van haat, ervaar. Dit is die mens se natuurlike reaksie in so 'n situasie. Wat doen hy/sy met daardie emosies? Psalm 
137 hou aan Christene voor dat hulle daardie emosies eerlik voor God, wat in elk geval weet dat die gelowige daardie emosies beleef, mag verwoord.

Dit is uiteindelik woorde van desperasie waarin God aangeroep word om reg en geregtigheid te laat geskied teenoor die slagoffer en sy oordeel te voltrek teenoor diegene wat God se wet oortree. God veroordeel sonde. Babel is deur Hom veroordeel (vgl Jes 13:1-22, 47:1-15; Jer 50:1-51:64). Die digter van Psalm 137 sluit dus aan by die profetiese oordeelsuitsprake teen Babel. So sluit die hedendaagse bidder van die psalm aan by Jesus se woorde in Johannes 16:8-11 waarin Hy sê dat die Heilige Gees onder andere sal kom om die wêreld te oordeel. Dit is eindelik 'n gebed dat God sy regverdige oordeel oor die misdadiger moet voltrek.

Die Christen mag Psalm 137 gebruik. Hy/sy mag, nee moet, sy/haar klaag- en wraakgedagtes vir God gee. Psalm 137 spreek van 'n verhouding wat die gelowige met God het waarin hy/sy eerlik met God kan en moet wees, waar hy al sy/haar negatiewe emosies, sy sug na wraak en reg en geregtigheid, kan verwoord en dit sodoende in God se hande plaas.

\section{GEBRUIKSMOONTLIKHEDE VAN PSALM 137}

Psalm 137 kan gebruik word op homiletiese, liturgiese en pastorale vlak asook as gebed. In die prediking kan die psalm gebruik word om aan te toon wat die Christen se respons op onreg en geweld behoort te wees. Soos reeds genoem, het die misdaadsituasie in Suid-Afrika tot gevolg dat baie Christene ook slagoffers daarvan geword het. Die gelowige se respons hierop behoort nie die opneem van die wapen te wees nie, maar die artikulering van alle emosies en wraakgedagtes in die vorm van 'n klaaglied. Waar die klaaglied nie meer gebruik word nie, bestaan die gevaar dat die soeke na reg en geregtigheid uit die samelewing kan verdwyn (Brueggemann 1995:107). Misdaad en onreg kan nie stoïsyns deur die kerk aanvaar word in die gesindheid van 'laat Gods water oor Gods akker loop' nie, maar daar moet met drif en emosiebelaaide metafore met God dialoog gevoer word, sodat Hy iets kan doen om reg te laat geskied. Die Christen moet geleer word dat sy respons op geweld en onreg nie is om wraak in eie hande te neem nie, maar dit in God se hande te plaas.

Die gebruik van die psalm in gebed en in 'n pastorale gesprek staan in lyn hiermee. In gebed moet al hierdie wraakgedagtes uitgespreek en eerlik tot God gerig word. In pastorale berading moet slagoffers van geweld die geleentheid gegee word om die volle intensiteit van hulle emosies te verbaliseer sodat daar genesing en vergifnis kan kom.

Die psalm kan ook in die liturgie van die kerk funksioneer as een wyse van spraak onder die koor van komplekse spreke oor God en tot 
God (Zenger 1996:92) in die vorm van sang of 'n drama (1996:90). Dit is absoluut essensieel dat die kerk erns moet maak met die weklikheid in ons land waar soveel mense gewelddadig misbruik en aangerand word. Die kerk het 'n verantwoordelikheid om toe te sien dat hierdie mense ook die geleentheid vind in die liturgie (miskien binne 'n selgroep) om hulle pyn, hulle smart, hulle wraak en begeerte om vergelding op 'n legitieme wyse te verbaliseer sodat dit in die hande van God gelaat kan word, wat self sal toesien dat reg en geregtigheid geskied.

\section{Literatuurverwysings}

Allen, L C 1983. Psalm 101-150. (WBC 21.) Waco: Word.

Anderson, A A [1972] 1981. The book of Psalms Vol 2, Psalms 73-150 (NCBC.) Paperback. Grand Rapids: Eerdmans.

Bright, J 1975. The authority of the Old Testament. Grand Rapids: Baker Book House.

Brueggemann, W 1984. The message of the Psalms. Minneapolis: Augsburg.

-, 1986. Praying the Psalms. Winona: St. Mary's Press.

-, 1995. The Psalms and the life of faith, ed by P D Miller. Minneapolis: Fortress.

-, 1997a. Cadences of home: Preaching among exiles. Louisville: Westminster John Knox Press.

-, 1997b. Theology of the Old Testament: Testimony, dispute, advocacy. Minneapolis: Fortress.

Burden, J J 1991. Psalms 120-150 (SBG.) Kaapstad: N G Kerk-uitgewers.

Fohrer, G 1993. Psalmen. Berlin: Walter de Gruyter (De Gruyter Studienbuch).

Holladay, W L 1993. The psalms through three thousand years. Minneapolis: Fortress.

Kellerman, U 1978. Psalm 137. ZAW 90 (1), 43-58.

Kraus, H-J 1989. Psalms 60-150, tr by H C Oswald. Minneapolis: Augsburg Fortress.

Levine, H J 1995. Sing unto God a new song. Bloomington \& Indianapolis: Indiana University Press.

McCann, J C 1993. A theological introduction to the book of Psalms. Nashville: Abingdon.

Mays, J L 1994. Psalms. Louisville: John Knox (Interpretation).

Pleins, J D 1993. The Psalms: Songs of tragedy, hope and justice. Maryknoll, NY: Orbis.

Von Rad, G 1962. Old Testament Theology, Vol 1. New York: Harper \& Row.

Waaijman, K 1986. Psalmen vanuit de Ballingschap. Kampen: Kok.

Weiser, A 1962. The Psalms, tr by H Hartwell. London (OTL) SCM.

Zenger, $\mathrm{E}$ 1996. A God of vengeance? Understanding the psalms of divine wrath, tr by L M Maloney. Louisville: Westminster John Knox Press. 